\title{
Analysis of the forest covers dynamics in the Samur-Yalama National Park of Azerbaijan*
}

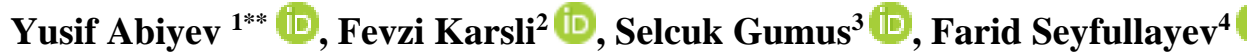 \\ ${ }^{1}$ Central Botanical Garden of ANAS, Department of Information Technology, AZ1004, Baku, Azerbaijan \\ ${ }^{2}$ Karadeniz Technical University, Faculty of Engineering, 61080 Trabzon, Turkey \\ ${ }^{3}$ Karadeniz Technical University, Faculty of Forestry, 61080 Trabzon, Turkey \\ ${ }^{4}$ Central Botanical Garden of ANAS, Lab of Monitoring and Conservation of Plants, AZ1004, Baku, Azerbaijan
}

\begin{abstract}
Most forests in Azerbaijan are distributed in mountain ecosystems, and lowland forests cover very small area. The biodiversity of Caspian coastal lowlands has come face-to-face with the danger of depletion over the last 100 years. At the present, their main broad-leaved forest example remains in the Samur-Yalama zone. Due to a strong anthropogenic impact, forest-covered areas are decreasing. From this point of view, a comprehensive study of the forests of the Samur-Yalama National Park is of special importance. In the studying of the dynamics of the forest cover, the spectral vegetation indices are main technique. The aim of the research is to analyze the forest covers dynamics by using the Normalized Difference Vegetation Index for the Samur-Yalama National Park of Azerbaijan. For this study, multi-spectral images were obtained from the Landsat 5 TM and 8 OLI program of the United States between 1984-2019 years. According to the analysis, the dynamics of forest cover development show a negative value and gradually replacement of the densely forested areas by sparse forest-shrub vegetation. Although the overall condition of forests has deteriorated in recent years and it has been considered to fit the category of moderately healthy forests. If this decrease will continue with current speed, then next decades' forests will move towards the weak healthy forests. That is why it needed to increase management, protection and awareness activities.
\end{abstract}

Keywords: Remote Sensing, Normalized Difference Vegetation Index, Forest, Landsat Images, Change Detection

\section{Introduction}

Caspian coastal ecosystem is most of the biologically rich regions and broad-leaved forests that occupy large areas can be distinguished significant biotope for the ecological view of point in Azerbaijan (Asadov et al., 2008). Coastal lowland forests have changed dramatically under the pressure of environmental and anthropogenic factors over the last 100 years (Mehdiyeva et al., 2017). Especially, increasing of stress and declines of species threaten the persistence of the biodiversity in the Samur-Shabran lowland which is situated the north-eastern of Azerbaijan in a flat plain between foothills of the Greater Caucasus and the coast of the Caspian Sea (Asadova et al., 2019). According to fertile soil, large forest areas were used for agriculture, also the reforestation here is difficult due to the low precipitation and other factors (Gurbanov, 2015). At present, relevant remains can be found in the Yalama massif, which has been given a national park status for the protection of the coastal forest ecosystem (Mirzayev and Sadikhova, 2009). There is sorely need comprehensive monitoring of processes in the forest cover which will create a scientific foundation for understanding interactions between human and natural phenomena (Schmidt and Uppenbrink, 2009). On the other hand, studying forest changes by spatial-temporal interpretation is inevitable preconditions for prognosis, planning of management strategies, and sustainable protection of biodiversity (Arlington, 2010).

The abundant data produced by optical remote sensing technology are the key times and spatially information on the understanding of the processes of forest ecosystems in the micro and macro-region (Bayramov et al., 2019). The principle of operation of remotely sensed imagery is interpreted on the differential absorption, transmission, and energy reflection of the electromagnetic spectrum, such as red, blue, green, and infrared using passive sensors (Fescenko and Wohlgemuth, 2017). Landsat, SPOT, QuickBird, RapidEye, IKONOS, WorldView, ASTER, MODIS, Radarsat, etc., provide a multi-temporal image dataset (Reyadh and Venkataraman, 2019). Especially, the Landsat database is a valuable source because of free

\footnotetext{
${ }^{*}$ This work has been partially presented in FETEC2019 Symposium

**Corresponding author: Tel: +994 553565957 E-mail: yusif.abiyev@ gmail.com 
downloading, long-term availability of systematically acquired images, spanning over 40 years, large coverage, and $30 \mathrm{~m}$ resolutions (Ke et al., 2015).

Over the years, many spectral vegetation indices (SVIs) had developed as the Difference Vegetation Index (DVI), the Relative Vegetation Index (RVI), Enhanced vegetation index (EVI), the Normalized Differential Vegetation Index (NDVI), based on the same principle for indexing the surface of the Earth, especially vegetation (Xue and Baofeng, 2017). The Normalized Difference Vegetation Index (NDVI) is one of the most frequently used standard algorithms and it was proposed by based on differences in pigment absorption features in the red and near-infrared bands of the electromagnetic spectrum (Al-Obaidey, 2019). NDVI is a good indicator to quickly identify monthly, annual, and decadal changes, state of health, the vigor of growth, and productivity of vegetation by using multi-temporal data and spatial criteria (Prasad et al., 2015). It can be used to relate chlorophyll content, so if the value is closed to 1 , it is an indicator of healthy vegetation (green content). The value of 0.1 or less represents the area of barren rock, sand, and snow; the value range from 0.2 to 0.5 shows shrubs, grassland, and senescence crops, and 0.6 to 0.9 represents dense vegetation (Yengoh et al., 2016).

The substantial study of the dynamics of forest changes by remote sensing has not been carried out in the Samur-Yalama National Park. For this reason, this article is of importance in terms of studying the processes in the region. This will also play a role in predicting changes that may occur in the future through comprehensive monitoring in the study area. The aim of the research is the analysis of the forest covers dynamics for the SamurYalama National Park by using the Normalized Difference Vegetation Index on the Landsat 5 TM and Landsat 8 OLI satellite imagery between 1984-2019 years.

\section{Material and Methods \\ 2.1. Study Area}

Samur-Yalama National Park (SYNP) was established in 2012 within the framework of the "South Caucasus Environmental Program" with financial support from the German Development Bank (KfW) and international consultants (MENR, 2014). The National Park is situated in the north-eastern part of Azerbaijan (in border of the Russia) and on the coast of Caspian Sea (Ismayilov and Jabrayilov, 2019). The Samur-Yalama National Park covers 11172 ha sized area on the coast of the Caspian Sea (Figure 1). Altitude is changed between -15 and $65 \mathrm{~m}$ (Ismayilov and Jabrayilov, 2019). Main corner coordinates are $41^{\circ} 37.632^{\prime} \mathrm{N}, \quad 48^{\circ} 41.460^{\prime} \mathrm{E}$; $41^{\circ} 39.618^{\prime} \mathrm{N}, 48^{\circ} 47.258^{\prime} \mathrm{E} ; 41^{\circ} 50.547^{\prime} \mathrm{N}, 48^{\circ} 35.549^{\prime} \mathrm{E}$; $41^{\circ} 46.911^{\prime} \mathrm{N}, 48^{\circ} 33.356^{\prime} \mathrm{E}$.

The land use is characterized by board-leaved forest in the lowland area, grassland or agriculture, and settlements (MENR, 2014). Climate is dry, hot semideserts, and dry steppes with mild winter. The average annual temperature is $+12.3{ }^{\circ} \mathrm{C}$, the hottest months are July and August (average $+27{ }^{\circ} \mathrm{C}$, absolute maximum $38-43{ }^{\circ} \mathrm{C}$ ), and the coldest is January (average $1{ }^{\circ} \mathrm{C}$ ). The smallest annual rainfall is $185 \mathrm{~mm}$ and the largest is 390 $\mathrm{mm}$. The relative humidity is 76 (Atlas of Ecology, 2009).

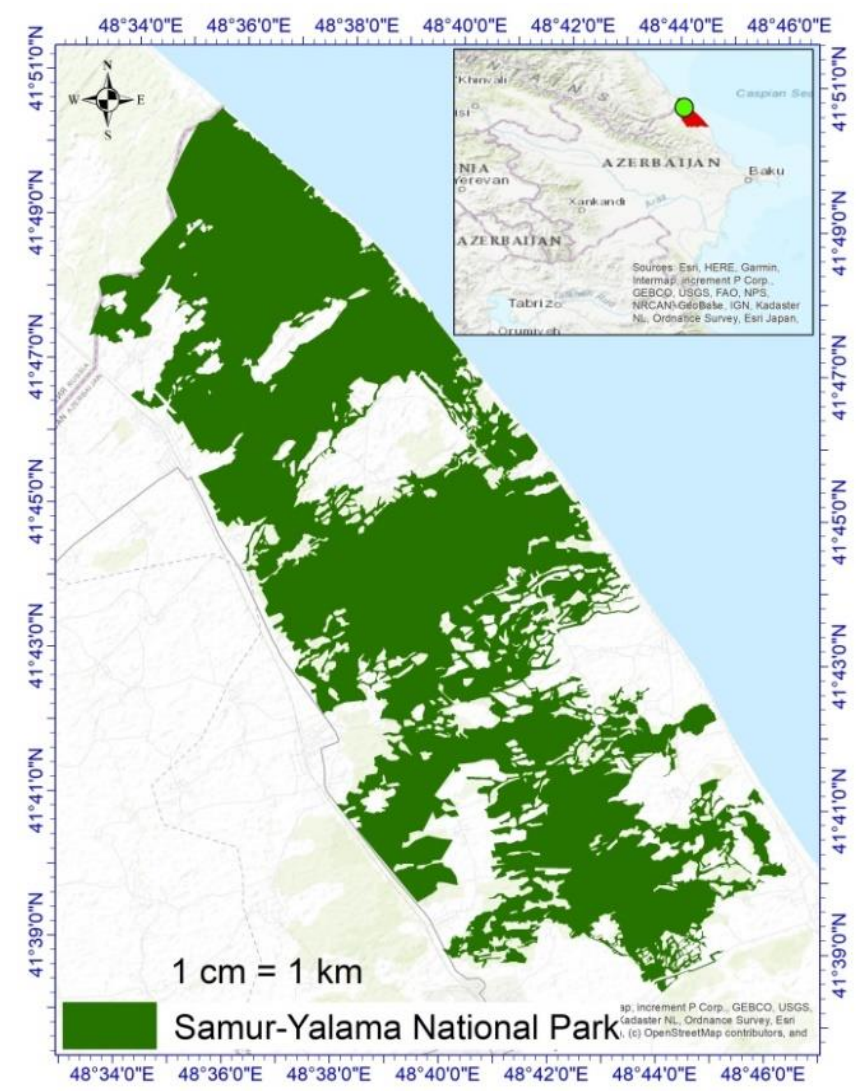

Figure 1. Map of the Samur-Yalama National Park 
Depending on the groundwater level and soil moisture, the vegetation composition of the Yalama forests is different (Mehdiyeva et al., 2017). The dominated species are oak (Quercus pedunculuflora K.Koch., Q. pubescens), European hornbeam (Carpinus caucasica Grossh.), field elm (Ulmus minor Mill.), field maple (Acer campestre L.) are the dominant tree species. In the temporal herbaceous areas white poplar (Populus alba L.), and swampy parts alder (Alnus glutinosa sub barbata C.A. Mey.) (Asadova et al., 2019). According to the development of tourism and agriculture, the research area can be considered a particularly vulnerable ecological zone (Dieterich, 2012).

\subsection{Method}

NDVI was calculated by using the following formula (Chouhan and Rao, 2012; Meeragandhi et al., 2015):

$$
\text { NDVI }=\frac{\text { NIR-RED }}{\text { NIR+RED }}
$$

where "NIR" is near-infrared (Landsat 5 - Band 4; Landsat $8-$ Band 5) and "RED" is red (Landsat $5-$ Band 3; Landsat 8 - Band 4) in satellite images captured with the Landsat sensor. The NDVI values calculated from pixel values of NIR and RED are also tabulated to find out the extent and the area under different NDVI class intervals. The NDVI was computed temporally to understand the change of land cover during the study period since it is the most common measurement used for measuring vegetation cover.

\subsection{Data Acquisition and Processing}

For this study, multi-spectral images were acquired from Landsat 5 and Landsat 8 satellite in the Earth Resources Observation and Science (EROS) data center
(USGS) between 1984-2019 years. When selecting the images, attention was paid to the clear sky in the study area. For this reason, June has been chosen to keep the cloudiness close to zero and the plant's vitality to be high. There were no images for 2003 and 2012 years.

For attenuating geometric and radiometric variations on satellite images, the pre-processing techniques were used (Tan et al. 2011). In this work, the images from the sensor were registered to WGS 1984 UTM zone 39N. The boundary shapefile (.shp) of the study area was used to clip out the Samur-Yalama National Park for processing of the bands of the images.

NDVI analysis was performed in Matlab environment and ArcGIS 10.6 by using the same algorithm. This helps to better understand the vegetation cover. Thus, in ArcGIS 10.6, NDVI values are given over certain threshold intervals. In this study, these threshold ranges were classified as $\leq 0.3 ;>0.3-\leq 0.4 ;>0.4-\leq 0.5 ;>0.5-\leq 0.6$; and >0.6. In ArcGIS 10.6, the minimum, mean, maximum values of the area were obtained for all years and accordingly a detailed map was prepared. But in Matlab, calculations were carried out for each 10 years. During the programming, the vegetation cover was shown with the command $\mathrm{q}=$ (NDVI> threshold). For understanding the change in the forests cover, $0.5,0.6$, and 0.7 thresholds were selected as the criteria. In addition, the Matlab has provided the scatter plot due to the reflection of light in the pixels for each threshold (Matlab, 2019).

The maps were given for 10 years between 1989 and 2019 , and the statistical dynamics for the years between 1984 and 2019. The flowchart in Figure 2 shows the steps that have been taken in conducting this research.

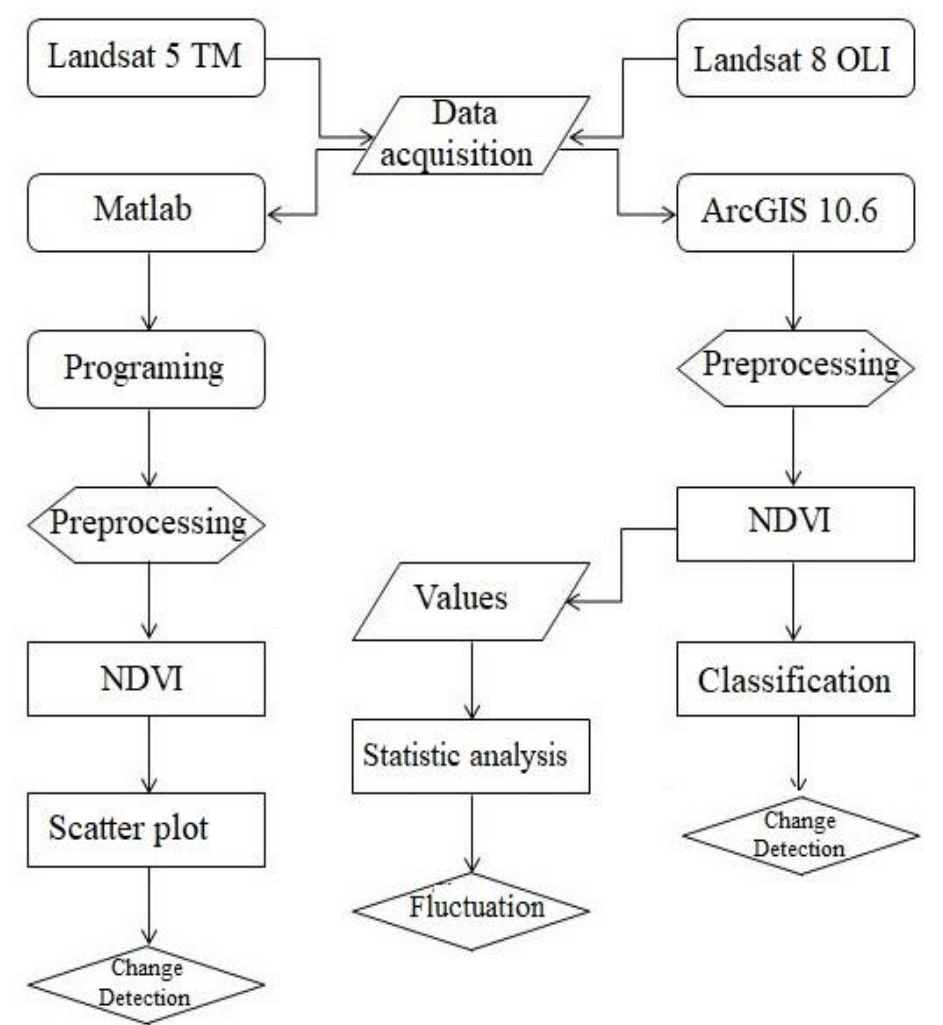

Figure 2. The flowchart of the study 


\section{Results}

\subsection{NDVI Classification}

The vegetation cover of the area was classified based on the results of NDVI for 10 years (Figure 3). According to the analysis, the dynamics of forest cover development showed a negative value and gradually replacement of the densely forested areas by sparse forest-shrub vegetation. Significant negative changes have been observed in the last 2 periods. In 2019, the average value of the total area was 0.47 , and the average value of forests was 0.55 . From this point of view, the forests of the Samur Yalama National Park are considered to fit the category of moderately healthy forests.

\subsection{Change for Each Threshold Among Periods}

The results of the analysis for each high vegetation value are as follows with a period of 10 years (Figure 4$6)$ :

- The 0.5 - Changes were less observed on result images.

- 0.6 - vegetation was decreased along the border with the tourism and agricultural areas of the forests. In the last period, a vegetation cover declined sharply.

- 0.7 - vegetation covers a large area only in 1989 , in the next periods the area of the highest healthy forests is almost zero.
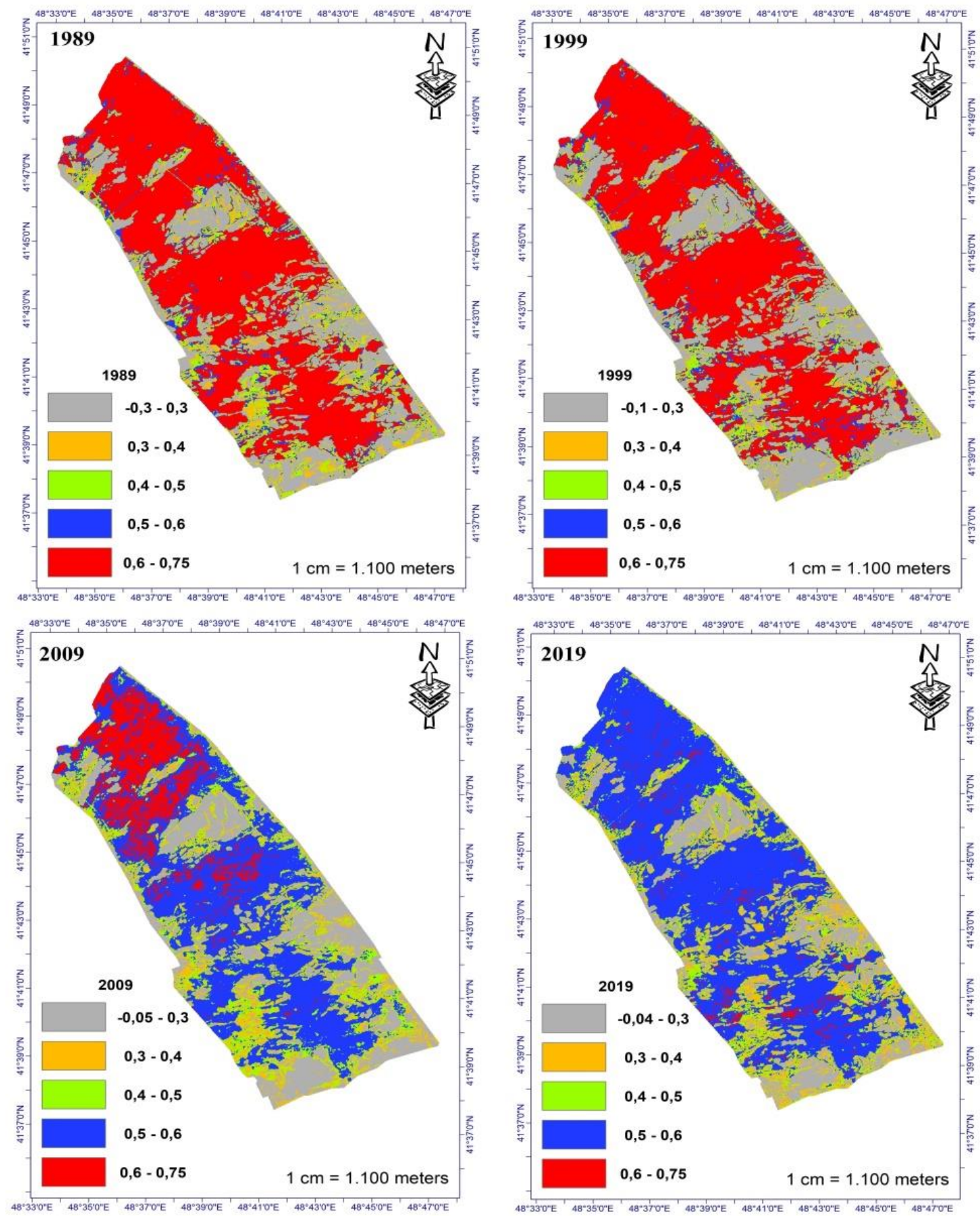

Figure 3. Comparisons of the vegetation cover by NDVI classification 


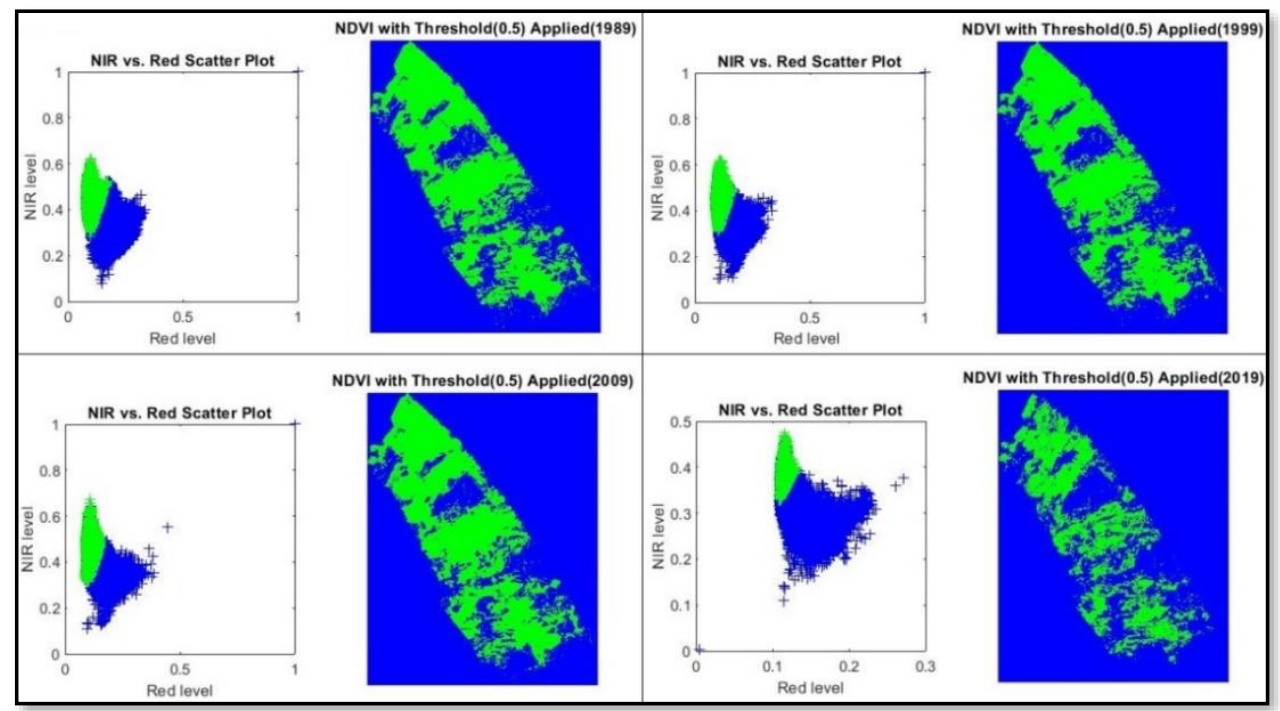

Figure 4. Comparisons of the vegetation cover corresponding to the value of 0.5 .

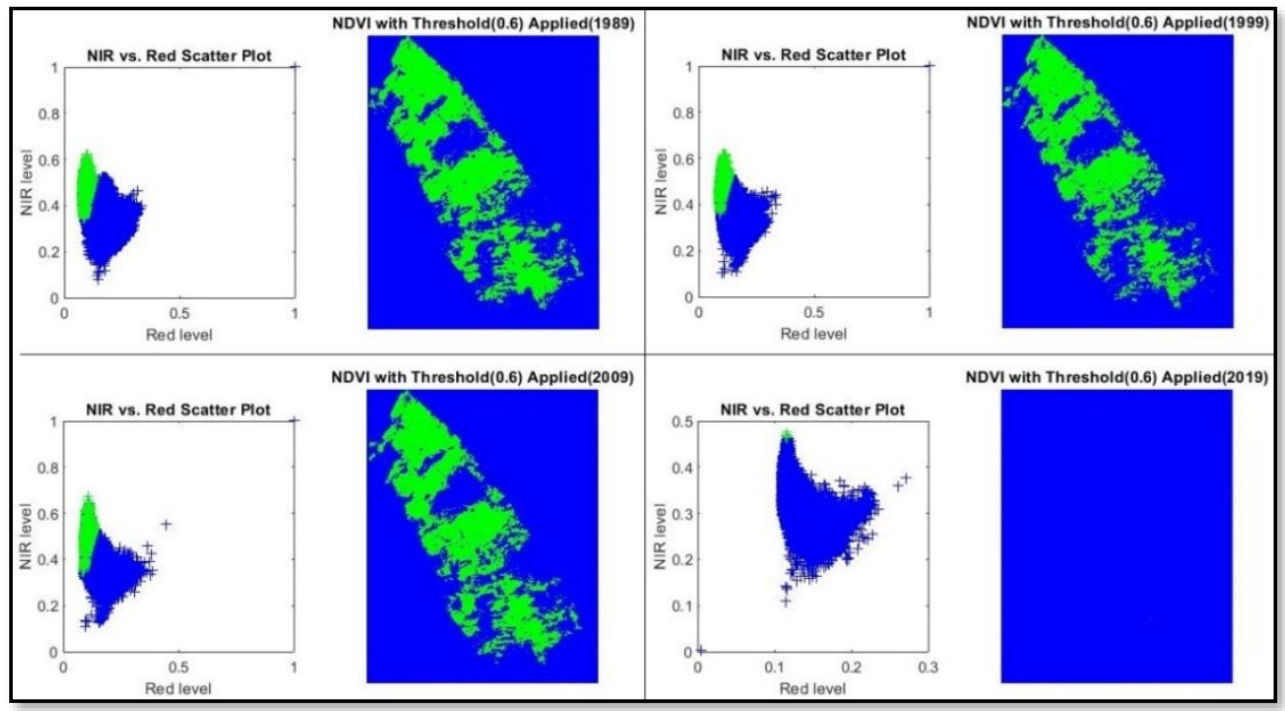

Figure 5. Comparisons of the vegetation cover corresponding to the value of 0.6.

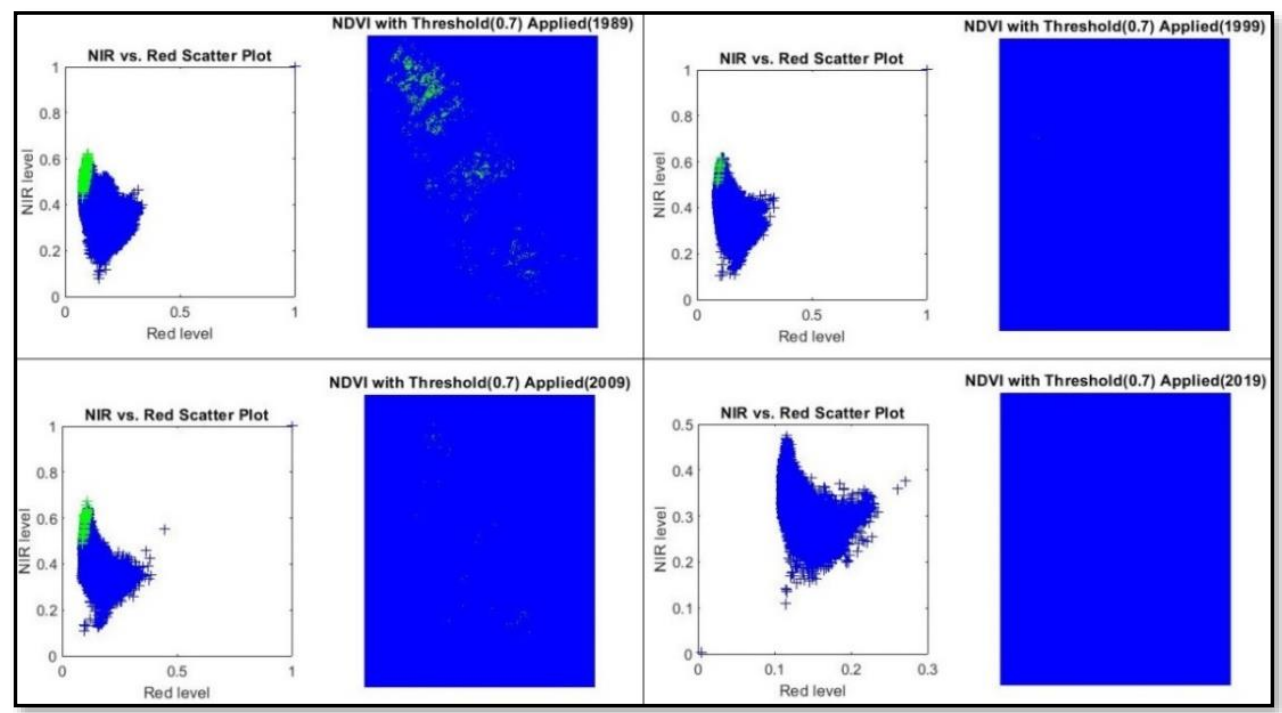

Figure 6. Comparisons of the vegetation cover corresponding to the value of 0.7 .

\subsection{The fluctuation of the NDVI}

According to the statistical dynamics, maximum, and mean NDVI values are as follows (Figure 7):

- the highest maximum value was 0.78 in 1995,
- the lowest maximum value was 0.60 in 2016 ,

- the highest mean value was 0.58 in 1995 ,

- the lowest mean value was 0.36 in 2001 . 


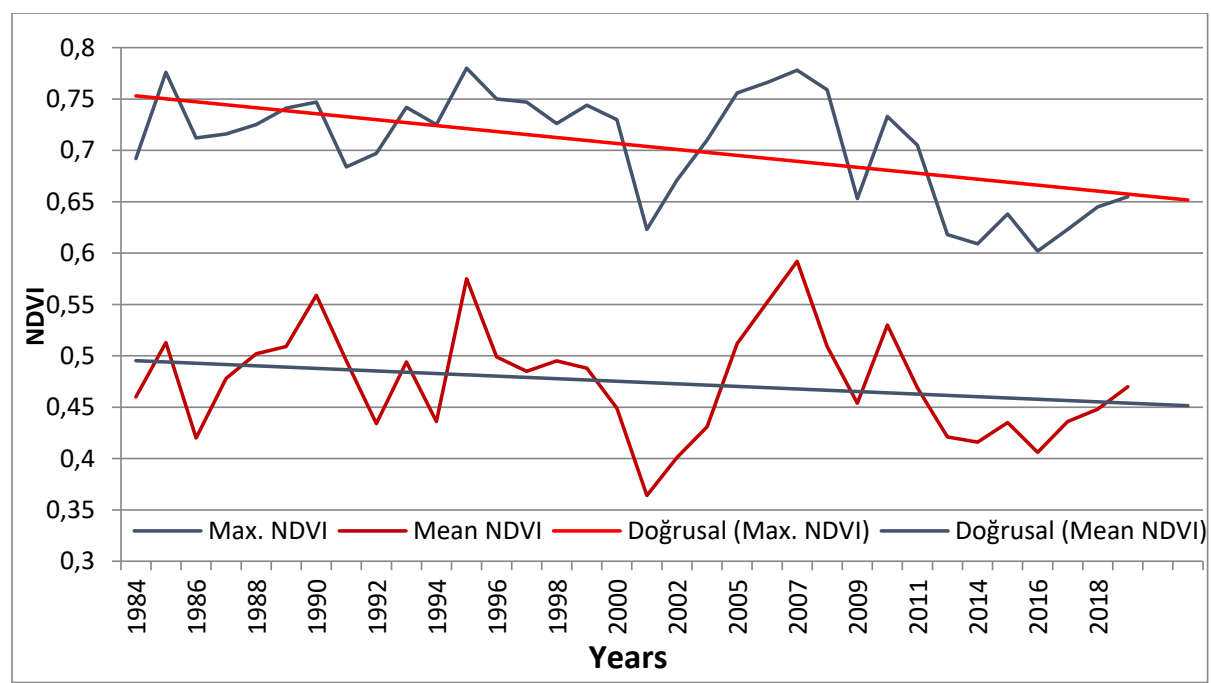

Figure 7. Fluctuation of maximum, mean indicators of the NDVI

\section{Discussion}

Usually, the decrease of the NDVI dynamics indicates stress due to a lack of water or extremely high temperatures for the plants, leading to a reduction of the photosynthetic rate and ultimately a qualitative and quantitative degradation of plants. Based on the results, the probabilities that led to the changes were assessed. Preview investigation in the Caspian shore zone showed that the process of desertification has taken place in some coastal parts of Azerbaijan (Abbasova, 2010). A deforestation was also observed in a similar study focused on the coastal zone (Caspian Sea) of the southeastern of Azerbaijan and anthropogenic influences have been cited as the main reason for these changes (Guliyev et al., 2015). According to a study that analyzed the change of the landscape between the years 2002 and 2019 in Azerbaijan along the Kura River, it was found that the area with high NDVI values decreased to 0 , while the areas with low NDVI values increased (Amanova et al., 2019). The authors attributed this to the ongoing desertification process in the region. However, there is no confirming source of degradation and erosion in Samur-Yalama National Park in the last years (Asam et al., 2019). In the past (prior to this study years), oak and elm forests have dried up en masse due to diseases and pests. For this reason the Quercus pedunculuflora C.Mey. forests were replaced gradually by the Carpinus caucasica forests during long term (Mirzayev and Sadikhova, 2009).

The scientific literature and official data do not mention the mass extinction of plant species in the forests of the National Park in the last 10 years. At the same time, there has been small positive change since the area was given national park status. The natural reforestation of the Carpinus caucasica is higher than other species. However, the scope reforestation and other forest plantations did not support to restore its previous dense structure of the main forest. Fires and other natural calamity states have not been registered according to official letter of the Ministry of Emergency Situations of Azerbaijan for the last 10 years. The proximity of groundwater (1-3 m) to the surface increase soil humidity (max. $75 \%$ ) and enrich surface vegetation in these areas. Thus, above mentioned factors reduce the risk of fire.

Statistical analysis was conducted among the average values of the obtained chlorophyll index, the average temperature of the same month (June), also the amount of monthly precipitation (May and June). There was not found any correlation (Figure 8-10).

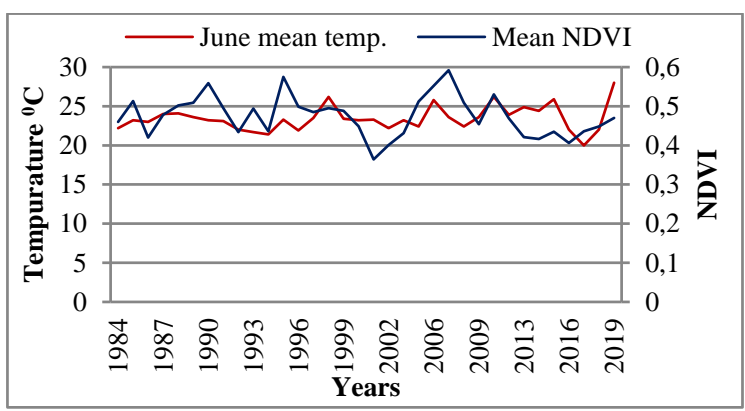

Figure 8. Correlation between mean temperature and NDVI

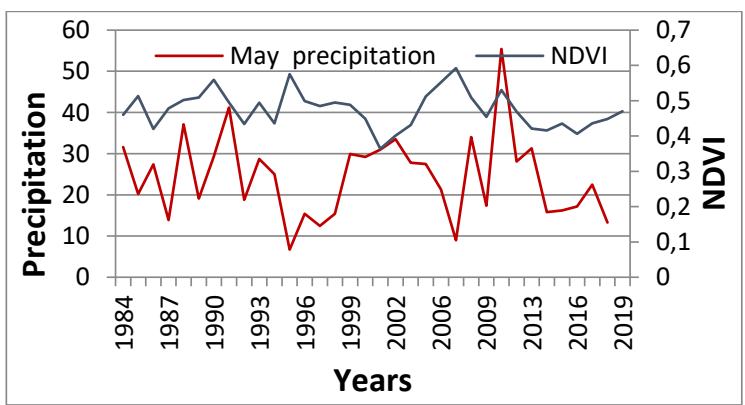

Figure 9. Correlation between May precipitation and NDVI

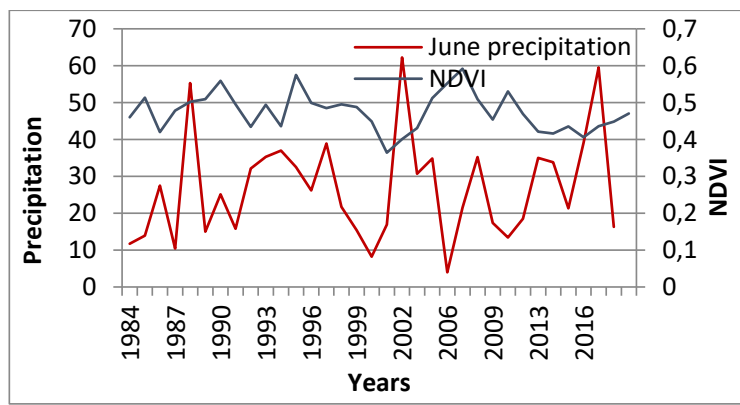

Figure 10. Correlation between June precipitation and NDVI 
These indicators can be considered normal due to the climate type (temperate) of the area. At same time because, anomaly weather was usually not observed in the area. During the time of this research, the average temperature varied $+22-+24{ }^{\circ} \mathrm{C}$ (max. is $+28{ }^{\circ} \mathrm{C}$ ). According to the similar studies carried out in the other countries, broadleaved forests show the similar results. Researchers conducted analyzes and reached the similar results reported that temperature is positively correlated with plant growth in the early and late growing season and negatively influences plant growth during midsummer (Wang et al., 2001). Chuai et al. (2013) showed that fluctuations in temperature did not obviously correspond with fluctuations in NDVI for broadleaf forests. Temperature is not a limiting factor for vegetation growth in summer. Long-term high temperature accelerates the evapotranspiration, potentially aggravates the water deficiency, as a result, and it suppress the growth of vegetation (Zhongbao et al., 2007). The scope of these factors does not strongly affect the process of photosynthesis in forests. Also, there weren't observed any correlations between climate parameters (monthly temperature and precipitation) and annual radial growth in the previous tree ring investigations on chestnut-leaved oak (Quercus castaneifolia C.A.Mey.) in the Samur-Yalama National Park. They explained that trees have no water stress and independent from most of the climate due to the high level of the groundwater (Seyfullayev, 2013).

The Samur-Yalama National Park's area and the outline thus imply potential land-use conflicts among conservation, agriculture and tourism. Previously carried out investigations stated that soil compaction increases negatively affecting radial growth $(25.9 \%)$, soil biochemical composition and biological activity (2 times) (Ismayilov et al., 2018). The results from these studies showed that the primary forest cover has been damaged and thinned due to long-term human forestry activities (illegal cutting, grazing etc.). Due to the lack of natural gas, households with low income appear to still rely on illegally collecting firewood in the forests and using the latter as pasture for livestock (Arnegger et al., 2014).

\section{Conclusions}

In this paper, the dynamics of the forest cover of Samur-Yalama National Park was assessed by multispectral images of the Landsat satellite and the Normalized Difference Vegetation Index method. To confirm the NDVI values, the calculations were performed on different images taken in the different months and near areas. The obtained values were the same with a difference of maximum \pm 0.05 . In addition, the applied the Chlorophyll Index green show same dynamics. The Chlorophyll Index green had a correlation of 0.78 with the NDVI:

$$
\text { CIgreen }=\frac{\text { NIR }}{\text { GREEN }}-1
$$

According to the analysis, the increase of the stress in the vegetation cover and the decrease in chlorophyll content are due to the decrease in vegetation density - the gradual replacement of densely forested areas with sparse forest-shrub. According to preliminary results, social pressure considered the main reason of the changes. Due to easy accessibility to the lowland forests, they have been subjected to more illegal cutting and other activities than mountain forests. Starting of the decline from near densely populated areas also proves these points. If this decrease will continue with current speed, then next decades' forests will move towards the weak healthy forests. That is why management, protection and awareness activities need to be increased.

The relationship among vegetation cover dynamics, climate and other influencing factors can be substantiated after extensive research. It will be possible to predict the chlorophyll content dynamics of vegetation cover change due to the result of wide research. However, the results obtained from this study will play a key role in future research. The experimental areas to be selected in the ground measurements should be placed in healthy and unhealthy areas based on the results of this study.

\section{Acknowledgements}

This research was carried out with the financial support of the Turkish Research Scholarship Program 2019 (№18AZ004196) in Karadeniz Technical University in Turkey and the Central Botanical Garden of Azerbaijan National Academy of Sciences within the PhD Thesis of Yusif Abiyev.

\section{References}

Abbasova, T., 2010. Detection and analysis of changes in desertification in the Caspian Sea Region. MSc. Thesis, Stockholm University, $67 \mathrm{p}$.

AL-Obaidey, E., 2019. The study of NDVI fluctuation in southern Iraq (Hor Ibn Najim) using remote sensing data. Al-Mustansiriyah Journal of Science. 30(1):1-6.

Amanova, S., Ismayilov, M., Guliyeva, I., 2019. Investigation of The Dynamics of Landscapes on The Basis of Vegetation Indication (Sample Area along Kura River). Ankara Üniversitesi Çevrebilimleri Dergisi, 7(2):14-25.

Arnegger, J., Dieterich, T., Rodina, V., 2014. Local awareness, acceptance, and tourism development: challenges and opportunities for protected area management in post-Soviet countries-the SamurYalama National Park, Azerbaijan. In: Proc. of the 7th International Conference on Monitoring and Management of Visitors in Recreational and Protected Areas. 20-23 August, Estonia. pp.148-150. Arlington, V., 2010. Biodiversity Analysis Update for Azerbaijan, United States Agency for International Development, Vol. I/II. 28 p.

Asadov, K.S., Mammadov, F.M., Sadikhov, S.A., 2008. Dendroflora and forests of the north-eastern part of 
the Greater Caucasus. Baku State University, Baku. 274 p.

Asadova, K.K., Abdiyeva, R.T., Mehdiyeva, N.P., Alizade, V.M., 2019. Forest Monitoring of Khachmaz District of Azerbaijan, Principles, and Methods. Biodiversity Conservation Materials, VII International Scientific Conference. 158-159.

Asam, S., Da Ponte, E., Köstl, T., Wuttej, D., Abbasov, S., Köppler, M., 2019. Mapping Grassland Extent and Degradation in Azerbaijan. ESA Living Planet Symposium, 13-17 May, Mailand, Italy.

Atlas of Ecology., 2009. Azerbaijan Republic, Baku Cartography Facility, Baku, 156 p.

Bayramov, E., Schlager, P., Kada, M., Buchroithner, M., Bayramov, R., 2019. Quantitative assessment of climate change impacts onto predicted erosion risks and their spatial distribution within the land cover classes of the Southern Caucasus using GIS and remote sensing. Modeling Earth Systems and Environment. 5:659-667.

Chouhan, R., Rao, N., 2012. Vegetation detection in multispectral remote sensing images: protective Roleanalysis of coastal vegetation in 2004 Indian Ocean Tsunami. Geo-Information for Disaster Management”, Procedia Technology, 6:612 - 621.

Dieterich, T., 2012. Report on Land Use and Rangeland Management in the future Samur Yalama National Park (Azerbaijan) and its support zone. 50 p. 10.13140/RG.2.2.17847.68005.

Fescenko, A., Wohlgemuth, T., 2017. Spatio-temporal analyses of local biodiversity hotspots reveal the importance of historical land-use dynamics, Biodiversity Conservation, 26: 2401.

Guliyev, F.A., Babayev, K.Y., Karimov, I.J., Tahirov R.I., Karimov R.T., 2015. The influence of anthropogenic factors on the soil and vegetative cover in the southeast part of Azerbaijan on the basis of space images. Annals of Agrarian Science 13(2).

Gurbanov, V., 2015. Ecological problems and protection against them caused by natural destructive processes in the north-east and south-western slopes of Greater Caucasus. Baku, 99.

Ismayilov, M., Amanova, S., Guliyeva, I., 2019. Investigation of the dynamics of landscapes on the basis of vegetation indication (Sample Area along Kura River). Ankara University Journal of Environmental Sciences, 7(2): 14-25.

Ismayilov, M., Jabrayilov, E., 2019. Protected Areas in Azerbaijan: Landscape-Ecological Diversity and Sustainability, Ankara University Journal of Environmental Sciences, 7(2): 31-42.

Ismailov, N.I., Alieva, G.J., Ismailova, P.M., Isaeva, H.E., 2018. Change in soil density in the forests of the forest park Samur-Yalama under the influence of recreational loads. Proceedings of the Central Botanical Garden of ANAS, XVI:277-283.
Ke, Y., Im, J., Lee, J., Gong, H., Ryu, Y., 2015. Characteristics of Landsat 8 OLI-derived NDVI by comparison with multiple satellite sensors and in-situ observations, Remote Sens. Environ., 164: 298-313.

MATLAB, 2019. MathWorks, Inc., MA https://www.mathworks.com/help/images/findingvegetation-in-a-multispectral-image. html

Meeragandhi, G., Arun, S.P., Thummala, N., Christy, A., 2015. Ndvi: Vegetation Change Detection Using Remote Sensing and GIS - A Case Study of Vellore District. Procedia Computer Science. 57: 1199-1210.

Mehdiyeva, N.P., Asadova, K.K., Abdiyeva, R.T., 2017. Monitoring the state of vegetation strip of the SamurDavachi lowland. Conference materials dedicated to the 90th anniversary of the Institute of Botany of ANAS and academician Vahid Jalal oglu Hajiyev of the Azerbaijan Botanical Society. Baku.

MENR, 2014. Ministry of Ecology and Natural Resources of Azerbaijan (MENR). KFW Kreditanstalt für Wiederaufbau and GFA Consulting Group.. Samur-Yalama National Park Report.

Mirzayev, O.H., Sadikhova, S.A., 2009. Influence of anthropogenic factors on licking forests and their modern ecological condition. Scientific Works of the Institute of Botany of ANAS, 29: 243-248.

Prasad, N., Semwal, M., Roy, P.S., 2015. Remote Sensing and GIS for Biodiversity Conservation. Springer India.

Reyad, A., Venkataraman, L., 2019. Comparison of Normalized Difference Vegetation Index derived from Landsat, MODIS, and AVHRR for the Mesopotamian Marshes Between 2002 and 2018. Remote Sensing. 11(10):1245.

Tan, K.C., Lim, H.S., Mat, J., Mohd, Z. Abdullah, K., 2011. A comparison of radiometric correction techniques in the evaluation of the relationship between LST and NDVI in Landsat imagery. Environ Monit Assess. 184: 3813-29.

Seyfullayev, F., 2013 Dendrochronological study of chestnut-leaved oak in the forests of Samur-Absheron lowland. Proceedings of the Central Botanical Garden of ANAS. 11: 147-155.

Schmidt, S., Uppenbrink, M., 2009. Potential Analysis for Further Nature Conservation in Azerbaijan: A Spatial and Political Investment Strategy, Greifswald: Michael Succow Foundation. 161 p.

Xue, J., Baofeng, S., 2017. Significant Remote Sensing Vegetation Indices: A Review of Developments and Applications. Journal of Sensors. 1-17.

Yengoh, G.T., Dent, D., Olsson, L., Tengberg, A.E., Tucker III, C.J., 2016. Use of the Normalized Difference Vegetation Index (NDVI) to Assess Land Degradation at Multiple Scales: current status, future trends, and practical considerations. Springer International Publishing AG. ISSN 2191-5547. Cham, Switzerland. 110 p. 